\section{Proactive changes in level of activity as a function of footshock and electroconvulsive shock treatments*}

\author{
RAYMOND P. KESNER and JOHN D'ANDREA \\ University of Utah, Salt Lake City, Utah 84112
}

The effects of electroconvulsive shock (ECS), footshock (FS), FS-ECS with zero delay, FS-ECS with 30 -sec delay, or no FS and no ECS (control) treatment upon 24-h activity levels were observed. All ECS-treated groups exhibited a marked decrease in level of activity on the first posttreatment day. The FS-ECS with zero delay group recovered completely on the second posttreatment day, while the ECS and FS-ECS with 30 -sec delay group recovered more slowly.

Previous research has indicated that recovery from electroconvulsive-shock(ECS) induced amnestic effects, although small incomplete, and unstable, occurs mainly when ECS is administered within a few seconds after a footshock (FS) (Kohlenberg \& Trabasso, 1968; Nielson, 1968; Riddell, 1969; Zinkin \& Miller, 1967). Thus, the possibility exists that the recovery from amnesia parallels the recovery from prolonged proactive changes that may result from the interactive effects of FS and ECS. A number of investigators have shown that FS treatments interact with ECS either by potentiating the proactive effects of ECS as indicated by enhanced catecholamine levels of the brain (Nielson \& Fleming, 1968) and facilitation of step-down latencies (Schneider, Malter, \& Advokat, 1969) or by interfering with proactive effects of ECS as indicated by a reduction in the incidence of electrical or behavioral seizure activity (Chorover \& De Luca, 1969; Pinel, 1971). However, the recovery functions from these FS-ECS-induced proactive changes have not been thoroughly investigated. One kind of proactive change induced by ECS has been reported by Stern (1957) and by Winder \& Stone (1946), who have shown that ECS treatments produce a reliable depression in activity levels for a $24-\mathrm{h}$ period. It is very possible that a combined FS-ECS treatment also produces a change in basal activity level, which could indirectly influence a latency measure often used as an index of retention. Thus, the purpose of the present study was to test for a possible interaction between FS and ECS upon both the initial depression in activity level and subsequent recovery from the treatment-induced depression in general activity level.

\section{SUBJECTS}

The Ss were 60 naive male Long-Evans hooded rats, 275-325 $\mathrm{g}$ at

*This investigation was supported by NIMH Grant MH-16918-03. the beginning of the experiment. APPARATUS

Wahmann activity wheels were used to measure activity. A smali microswitch was fitted to each wheel and connected to standard relay circuitry and Sodeco printout counters to record the number of revolutions every $30 \mathrm{~min}$.

\section{PROCEDURE}

Each animal was placed in an activity wheel, and the base level of activity was recorded for the first 6 days. Each animal was maintained throughout the experiment on ad lib food and water. On the seventh day, the animals were divided into two groups. The animals were treated either in the daytime (8 a.m.) or at night ( 8 p.m.), so that the treatments were counterbalanced with respect to their daily activity cycle. The animals were matched on the basis of the average 24-h activity level and further subdivided into five treatment groups of six animals each. Animals in the first group (FS only) were removed from their wheels, placed in a box, administered a FS (5 mA for $1 \mathrm{sec})$ and returned to their wheels. Animals in the second group (FS-ECS, immediate) and the third group (FS-ECS, $30 \mathrm{sec}$ ) were given a FS followed by ECS administered through earclips ( $35 \mathrm{~mA}$ for $.5 \mathrm{sec}$ ) with either zero delay or a 30 -sec delay, respectively. The rats in the fourth group (ECS only) received only an ECS treatment, and in the fifth group (no FS-no ECS) served as a control, receiving no FS and no ECS treatments. The activity levels were recorded for 3 days after the

Table 1

Mean Percent of Base Rate of Daily Activity for Each Treatment Group

Posttreatment

\begin{tabular}{lrrr}
\multicolumn{1}{c}{ Group } & Day 1 & Day 2 & Day 3 \\
\hline No FS, No ECS & 125.4 & 146.9 & 101.9 \\
FS Only & 107.4 & 101.9 & 77.0 \\
FS-ECS, Immediate & 32.0 & 98.0 & 117.3 \\
FS-ECS, 30 Sec & 41.9 & 52.5 & 87.4 \\
ECS Only & 30.9 & 62.0 & 58.3 \\
\hline
\end{tabular}

administration of the differential treatments.

The $1 / 2-h$ activity data were too variable and were therefore summed to obtain 24-h activity scores. Furthermore, within each treatment group, no differences were found between the daytime and nighttime treated animals, and thus they were combined. For each posttreatment day and for each animal, a percent change from a daily base rate based on activity of 3 days prior to treatment was calculated. The mean percent of base rate activity for each treatment group across the 3 posttreatment days is shown in Table 1 . The results show that all three ECS groups were markedly suppressed in level of activity on the first posttreatment day. The ECS-only group and the FS-ECS, 30 -sec group showed some recovery on the second and third posttreatment day, while the FS-ECS immediate group recovered completely on the second posttreatment day. The FS-only and no FS-no ECS groups showed no change in levels of activity throughout the 3 posttreatment days. A Treatment by Days analysis of variance with repeated measures on days indicated that change in level of activity was influenced by treatment $(\mathrm{F}=3.35, \mathrm{df}=4,55, \mathrm{p}<.03)$, days $(\mathrm{F}=4.63, \mathrm{df}=2,110, \mathrm{p}<.02)$, and the Treatment by Days interaction $(\mathrm{F}=3.59, \quad \mathrm{df}=8,110, \quad \mathrm{p}<.01) . \quad \mathrm{A}$ Newman-Keuls test analysis showed that on the first posttreatment day, each ECS-treated group showed significantly less activity than the control group $(p<.01)$ and the FS-only group $(\mathrm{p}<.05)$.

On the second posttreatment day, the ECS-only group and the FS-ECS, 30-sec group still showed a significant suppression of activity compared to the control group $(p<.01)$, but the FS-ECS, immediate group did not significantly differ from control. On the third posttreatment day, no significant differences were found. The control, FS-only, ECS-only, and FS-ECS, 30-sec groups did not change significantly in activity level across the 3 posttreatment days, although the FS-ECS, 30-sec group showed a marked recovery on the third posttreatment day. On the other hand, the FS-ECS, immediate group showed 
a significant recovery from the first posttreatment day depression in activity on the second $(p<.05)$ and the third $(p<.01)$ posttreatment days.

\section{DISCUSSION}

The results indicate that the immediate consequence of ECS or FS-ECS treatments is a marked reduction in general activity level. These findings are consistent with the results of Stern (1956) and Winder \& Stone (1946), who also report a suppression in the level of activity for $24 \mathrm{~h}$ after one or multiple ECS treatments. The most interesting finding was that the FS-ECS, immediate group exhibited complete recovery from the ECS-induced suppression of activity levels on the second posttreatment day. In contrast the recovery shown by the ECS-only and FS-ECS, $30 \mathrm{sec}$ groups on the second and third posttreatment days never returned to $100 \%$ of the pretreatment base rate level. These results suggest that when a FS precedes an ECS treatment with a short delay, the FS treatment interferes rather than potentiates the proactive depressive effects of ECS upon general activity levels. The profound recovery in level of activity between the first and second or third posttreatment day for the FS-ECS, immediate group parallels the reported recovery from ECS-induced amnestic effects and suggests the possibility that the general level of activity may in part have influenced changes in latency and thus indirectly attenuated the ECS-induced amnestic effects.

\section{REFERENCES}

CHOROVER, S. L., \& De LUCA, A. M Transient change in electrocorticographic reaction to ECS in the rat following footshock. Journal of Comparalive \& Physiological Psychology, 1969, 69, 141-149.

KOHLENBERG, R., \& TRABASSO, T Recovery of a conditioned emotional response after one or two electroconvulsive shocks. Journal of Comparative \& Physiological Psychology, $1968,65,270-273$.

NIELSON, H. C. Evidence that electroconvulsive shock alters memory retrieval rather than memory consolidation. Experimental Neurology,
$1968,20,3-20$.

NIELSON, H. C., \& FLEMING. R. M. Effects of electroconvulsive shock and prior stress on brain amine levels. Experimental Neurology, 1968, 20, 21-30.

PINEL, J. P. Disruption of ECS-induced seizures in rats by antecedent footshock. Communications in Behavioral Biology, $1971,6,79-85$.

RIDDELL, W. I. Effect of electroconvulsive shock: Permanent or temporary retrograde amnesia. Journal of Comparative \& Physiological Psychology, $1969,67,140-144$

SCHNEIDER, A. M., MALTER, A., \& ADVOKAT, C. Pretreatment effects of a single ECS and footshock plus ECS on step-down latencies of trained and untrained rats. Journal of Comparative \& Physiological Psychology, 1969, 68. 627-630.

STERN, J, A. The effect of a series of electroconvulsive seizures on some measures of activity in the male albino rat. Journal of Genetic Psy chology, 1956, 89, 141-151.

WINDER, C. L, \& STONE, C. P. Reduction in general activity in male albino rats from electroconvulsive shock. Proceedings of the Society of Experimental Biology, 1946, 63, 19-21.

ZINKIN, S. \& MILLER, A. J. Recovery of memory after amnesia induced by electroconvulsive shock. Science, 1967. $155,102-104$. 